Check for updates

Cite this: RSC Adv., 2019, 9, 22907

Received 20th June 2019

Accepted 11th July 2019

DOI: $10.1039 / \mathrm{c} 9 \mathrm{ra04641k}$

rsc.li/rsc-advances

\section{Removal characteristics of two anionic dyes by a polyethylenimine/poly $(N, N$-dimethylaminoethyl methacrylate) gel}

\begin{abstract}
Siwei Liang, ${ }^{a}$ Jingyi Tang, ${ }^{a}$ Shun Yao (D) *a and Weixia Zhu*b
The highly efficient gel obtained via the copolymerization of polyethylenimine (PEI) and poly $(N, N$ dimethylaminoethyl methacrylate) (PDMAEMA) was successfully applied for the removal of two anionic dyes (amaranth and sunset yellow) from their aqueous solutions. Moreover, the results of the adsorption experiments for sunset yellow and amaranth on the PEI/PDMAEMA gel demonstrate that the adsorption equilibrium both could be achieved within $1 \mathrm{~h}$, and the maximum adsorption capacities were $757 \mathrm{mg} \mathrm{g}^{-1}$ and $744 \mathrm{mg} \mathrm{g}^{-1}$ under unoptimized conditions, respectively. Moreover, the PEI/PDMAEMA composite gel was found to be $\mathrm{pH}$ sensitive and the addition of salts together with ionic strength were also explored for understanding the adsorption performance. In addition, it can be found from the studies of adsorption mechanism that it is mainly electrostatic adsorption; moreover, the separation process conforms to the Langmuir adsorption isotherm model and the pseudo second-order kinetic model, which is a spontaneous endothermic process. When the PEI/PDMAEMA gel was used in continuous flow column, it could handle large volumes of dye solution with very low concentrations due to its strong enrichment capacity. Finally, the desorption experiments show that the PEI/PDMAEMA gel is easier to regenerate and has a longer lifetime. Therefore, the high adsorption capacity and easy operation of adsorption for amaranth and sunset yellow on the PEI/PDMAEMA gel make it a potential application prospect for the practical removal of other kinds of similar pollutants.
\end{abstract}

\section{Introduction}

At present, a series of anionic synthetic pigments, which mainly include sunset yellow, carmine, amaranth, erythrosine, and fancy red, ${ }^{1}$ that are widely used in related industries (e.g., pharmaceutical, printing, dyeing, and food industries) have been found to be carcinogenic via animal experiments. In addition, some anionic synthetic pigments can aggravate the condition of asthma patients, some can result in allergies, and some can cause excessive activity in children. ${ }^{2}$ Thus, synthetic pigments have been banned in some countries. For example, the US Food and Drug Administration (FDA) prohibits the use of carmine, amaranth, and erythrosine, while all other synthetic pigments mentioned above are prohibited in Norway and some other countries. Undoubtedly, the intentional or unintentional discharge of these dyes into the aqueous environment can also lead to serious pollution and public health problems, which can not only cause the water body to be coloured but also reduce the amount of light transmitted through the water body, thereby affecting the photosynthesis of aquatic plants and causing

${ }^{a}$ School of Chemical Engineering, Sichuan University, Chengdu 610065, People's Republic of China. E-mail: cusack@scu.edu.cn; Fax: +86-28-8540-5221; Tel: +86-288540-5221

${ }^{b}$ School of Chemical Engineering and Energy, Zhengzhou University, Zhengzhou 450001, People's Republic of China. E-mail: lan.12tian@163.com damage to the entire aquatic ecosystem. When these chemicals are treated by adsorption, relatively ideal processing speed, high efficiency, and easy operation can be realized, while no extra chemicals are introduced. ${ }^{3}$ Meanwhile, the adsorption/ enrichment techniques can also be used in the analysis and detection of environmental hazards. Therefore, the research and development of various adsorbents are attracting increasing attention from researchers and engineers, which have become one of the hot issues in related fields.

Poly( $N, N$-dimethylaminoethyl methacrylate) (PDMAEMA) gel is a kind of temperature and $\mathrm{pH}$-sensitive hydrogel that automatically perceives small changes in external temperature and $\mathrm{pH}$ and responds to these changes by swelling or shrinking. Therefore, the properties of the PDMAEMA gel are closely related to the coupling degree, chemical composition, network structure, and external environment. ${ }^{4}$ In order to improve its adsorption capacity or to make it adaptable for more separation tasks, the gel is often chemically modified methods, such as the modification with amino groups on the polymer chains and copolymerization of the double bonds in the DMAEMA monomers. ${ }^{5}$ Alternatively, the functional groups can also be introduced into the molecular chain by modification and copolymerization, which can strengthen its interaction with the target substance. The double bond and amino groups in the DMAEMA molecules make it easy to introduce other functional groups, so there is still enough space for improvement in its adsorption capacity. 
Polyethylenimine (PEI) is a water-soluble polymer with a large amount of hydrophilic amine groups. The ratio of primary, secondary, and tertiary amine groups of PEI is $1: 2: 1$. The $\mathrm{N}$ atoms in the amine groups can chelate with the metal ions or combine with the hydrogen ions and then electrostatically react with the anions in the solution. ${ }^{6}$ This kind of polymer has been widely used in many fields, such as environmental chemistry and biomedicine. For example, a new adsorption material, $\mathrm{PEI}-\mathrm{SiO}_{2}$, was prepared by connecting polyethyleneimine (PEI) to the surface of silica gel, which was found to have ideal adsorption capacity for $\mathrm{Cr}(\mathrm{VI}), \mathrm{Cu}(\mathrm{II}), \mathrm{Zn}(\mathrm{II})$, and $\mathrm{Cd}(\mathrm{II}){ }^{7}$ After the modification of the material by a quaternary amine, a new adsorption material named Q PEI-SiO ${ }_{2}$ could be prepared to adsorb the chromate ions. ${ }^{8}$ Moreover, in the study by Tokuyama et al., ${ }^{9}$ the adsorption amounts of $\mathrm{Pt}(\mathrm{IV})$ and $\mathrm{Au}(\mathrm{III})$ ions on the PDMAEMA gel were $0.2542 \mathrm{mmol} \mathrm{g}^{-1}$ and $0.2351 \mathrm{mmol} \mathrm{g}^{-1}$, respectively.

Compared with the separation application for metal ions, the adsorption of anionic dyes by a relevant adsorbent composed of PDMAEMA or PEI is much less studied. Previously, CD/CA-gPDMAEMA was successfully synthesized by Zhou et al., with a maximum adsorption capacity of $335.5 \mathrm{mg} \mathrm{g}^{-1}$ and $165.8 \mathrm{mg}$ $\mathrm{g}^{-1}$ for a cationic dye (methylene blue, $\mathrm{MB}$ ) and anionic dye (methyl orange, MO), respectively. ${ }^{10}$ Although the adsorption capacity of the PDMAEMA gel is superior to that of traditional adsorbents, there are still some shortcomings. For instance, the adsorption method has a slower adsorption rate and is timeconsuming. It takes 7 days to reach the adsorption equilibrium when adsorbing heavy metal ions. ${ }^{9}$ Cheng also pointed out that the pore structure of PDMAEMA could limit its adsorption rate. ${ }^{11}$ However, there is still a rigid demand for further improvement in the adsorption capacity of the gel. A PEI nanofibrous membrane was synthesized for the adsorption of anionic dyes with a maximum adsorption capacity of $454.44 \mathrm{mg} \mathrm{g}^{-1}$ for amaranth, which demonstrates the outstanding adsorption performance of PEI. ${ }^{12}$ In a recent study, Dioscorea opposita Thunb. (DOT) was modified with polyethyleneimine (DOT@PEI) as a novel biosorbent for the removal of the typical anionic dye indigo carmine

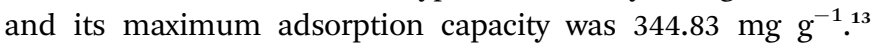
Therefore, it is expected that PEI with a large amount of hydrophilic amine groups can be copolymerized with PDMAEMA to increase the hydrophilicity and number of functional groups in the gel; thereby, preparing a PEI/PDMAEMA polymer gel with high adsorption rate and high capacity.

On the basis of the above-mentioned studies, in this study, the PEI/PDMAEMA gel was prepared via amine radical copolymerization method for studying its adsorption behaviours for two typical anionic dyes (amaranth and sunset yellow). The adsorption mechanism was further analyzed by adsorption isotherm, adsorption kinetics, and adsorption thermodynamics model. Finally, the static and dynamic desorption capacities were also evaluated for its regeneration.

\section{Experimental}

\section{Materials and reagents}

Amaranth $\left(\mathrm{C}_{20} \mathrm{H}_{11} \mathrm{~N}_{2} \mathrm{Na}_{3} \mathrm{O}_{10} \mathrm{~S}_{3}\right)$ and sunset yellow $\left(\mathrm{C}_{16} \mathrm{H}_{10} \mathrm{~N}_{2}\right.$ $\mathrm{Na}_{2} \mathrm{O}_{7} \mathrm{~S}_{2}$ ) were purchased from Kelong Chemical Company (AR, each of purity $>98 \%$, Chengdu, China). Branched polyethyleneimine (PEI) $\left(\bar{M}_{\mathrm{w}}=1800 \mathrm{~g} \cdot \mathrm{mol}^{-1}\right.$, the contents of primary, secondary, and tertiary amino groups were $35 \%, 35 \%$, and $30 \%$, respectively) was provided by Mengde Electroplate Chemistry Co., Ltd (specific electro-plating class, Jiangsu, China). 2-(Dimethylamino)ethyl methacrylate (DMAEMA) monomer, $N, N^{\prime}$-methylenebisacrylamide (MBAA) cross-linker, and azobisisobutyronitrile (AIBN) initiator were purchased from Puguang Industrial Co., Ltd. (each of purity $>99 \%$, Shanghai, China). All the solvents were of analytical grade or higher. Ultrapure water used in the experimental process was prepared using the ultra-pure water system ( $0.4 \mathrm{~mm}$ filter) from Ultrapure Technology Co. Ltd. (Chengdu, China).

\section{Quantitative analysis for anionic dyes and determination of their adsorption amount}

$1.0 \mathrm{~g}$ of amaranth or sunset yellow was weighed and completely dissolved in distilled water and then, the solution was transferred to a $100 \mathrm{~mL}$ volumetric flask to prepare the standard solutions of $10.0 \mathrm{~g} \mathrm{~L}^{-1}$. Before the adsorption experiments, some stock solution was taken and the volume was adjusted to $50 \mathrm{~mL}$ by the distilled aqueous solution to a certain $\mathrm{pH}$ value, which was added to $\mathrm{HCl}$ or $\mathrm{NaOH}$ solution, and then two kinds of pigment standard solutions under different $\mathrm{pH}$ conditions were obtained. Then, a certain amount of amaranth or sunset yellow test solution was pipetted into a $50 \mathrm{~mL}$ colorimetric tube and diluted to the graduation with redistilled water. Subsequently, its absorbance was measured at $521 \mathrm{~nm}$ or $482 \mathrm{~nm}$ via ultraviolet spectrophotometry. ${ }^{\mathbf{1 4 , 1 5}}$

$1 \mathrm{~mL}$ of $10.0 \mathrm{~g} \mathrm{~L}^{-1}$ amaranth solution was diluted to $100 \mathrm{~mL}$ to obtain the $100 \mathrm{mg} \mathrm{L}^{-1}$ amaranth standard solution. Then, 0 , $1.00 \mathrm{~mL}, 2.00 \mathrm{~mL}, 3.00 \mathrm{~mL}, 4.00 \mathrm{~mL}, 5.00 \mathrm{~mL}, 6.00 \mathrm{~mL}, 7.00 \mathrm{~mL}$, and $8.00 \mathrm{~mL}$ of the amaranth standard solution was added to a series of $25 \mathrm{~mL}$ colorimetric tubes. According to the UV-Vis spectroscopic method of amaranth, which is mentioned above, the standard curve for amaranth was obtained as $y=$ $0.02222 x+0.01000\left(R^{2}=0.9992\right)$, where $y$ was the measured absorbance of the samples at $521 \mathrm{~nm}$ and $x$ was its amount (mg) in the samples.

Similarly, $1 \mathrm{~mL}$ of $10.0 \mathrm{~g} \mathrm{~L}^{-1}$ sunset yellow solution was diluted to obtain a $100 \mathrm{mg} \mathrm{L}^{-1}$ sunset yellow standard solution. Then, $0,1.00,2.00,3.00,4.00,5.00,6.00$, and $7.00 \mathrm{~mL}$ of the sunset yellow standard solution was added to a series of $25 \mathrm{~mL}$ colorimetric tubes. According to the UV-Vis spectroscopic method of sunset yellow, which is mentioned above, the standard curve of sunset yellow was obtained as $y=0.04570 x-$ $0.01350\left(R^{2}=0.9996\right)$, where $y$ was the measured absorbance of the samples at $482 \mathrm{~nm}$ and $x$ was its amount (mg) in the samples.

\section{Preparation of the PEI/PDMAEMA gel}

On the basis of the developed copolymerization strategy in current reports, the DMAEMA monomer, MBAA coupling agent, and AIBN initiator were placed in a beaker and mixed uniformly. ${ }^{16}$ Then, ethanol and a certain concentration (0-8\%) of the PEI aqueous solution were added dropwise and the raw 
materials were dissolved by mechanical shaker. After that, the mixture was magnetically stirred in a nitrogen atmosphere, then poured into a test tube, sealed quickly, and placed in a constant temperature water bath $\left(30-90{ }^{\circ} \mathrm{C}\right)$ for a certain duration (1-6 h). At the end of the reaction, the test tube was immersed in an ice bath of $0{ }^{\circ} \mathrm{C}$ for cooling. The gel was taken out and washed with distilled water for further use.

\section{Adsorption experiments}

Static adsorption experiment. $50 \mathrm{~mL}$ of the amaranth or sunset yellow standard solution (200-1600 $\mathrm{mg} \mathrm{L}^{-1}$ ) with different $\mathrm{pH}$ values (1-5) was loaded in a conical flask, and then, it was mixed with $0.05 \mathrm{~g}$ PEI/PDMAEMA gel. Further, the conical flask was sealed and placed in a water-bath shaker $\left(30-50{ }^{\circ} \mathrm{C}\right)$ whose temperature and vibration intensity were set beforehand. After shaking for a certain period of time (0-120 min), the adsorption equilibrium was achieved and the supernatant was taken to measure the anion concentration. The adsorption capacity for the anion was calculated according to the following equation:

$$
Q=\frac{V \times\left(C_{0}-C_{t}\right)}{M_{0}}
$$

where $Q$ is the adsorbed amount of anion on the gel $\left(\mathrm{mg} \mathrm{g}^{-1}\right), V$ is the volume of the adsorption solution $(\mathrm{mL}), M_{0}$ is the dry weight of the gel adsorbent $(\mathrm{g}), C_{0}$ is the initial concentration of the anion solution $\left(\mathrm{mg} \mathrm{L}^{-1}\right)$, and $C_{t}$ is the concentration of the anion solution after adsorption $\left(\mathrm{mg} \mathrm{L}^{-1}\right)$.

Dynamic adsorption experiment. The PEI/PDMAEMA gel was compactly packed in a glass column $(5 \times 1 \mathrm{~cm})$ and then, a certain concentration of amaranth or sunset yellow solution (200-1600 $\mathrm{mg} \mathrm{L}^{-1}$ ) was sequentially added into each gel column. The solution was passed through the adsorption column at $0.2 \mathrm{~mL} \min ^{-1}$ and then sampled at the outlet. The concentration of the anion in the effluent was measured until the concentration was the same as that at the inlet and then the continuous loading was stopped. Taking the bed volume as the abscissa and the ratio of the anion concentration at the outlet to the anion concentration at the inlet as the ordinate, the dynamic penetration curve of amaranth and sunset yellow can be plotted. According to the empirical value, ${ }^{\mathbf{1 7}}$ the penetration point was defined by selecting the point when the anion concentration in the effluent reached $10 \%$ of the initial concentration.

\section{Results and discussion}

\section{Reaction mechanism and conditions for the preparation of the PEI/PDMAEMA composites}

Polyethylenimine (PEI) possesses a number of amine functional groups that can react with the initiator azobisisobutyronitrile (AIBN) to form redox couples. First, an electron on the nitrogen transfers to AIBN to form a nitrogen radical $\left(\mathrm{N}^{*}\right)$ and an alkyl radical $\left(\mathrm{C}^{*}\right){ }^{18,19}$ Then, the $-\mathrm{NH}_{2}$ group on PEI loses a proton to form an amine radical $\left(\mathrm{NH}^{\circ}\right)$, which can be copolymerized with a double bond on DMAEMA to form PEI/PDMAEMA. In addition, the generated alkyl radical $\left(\mathrm{C}^{*}\right)$ can also copolymerize with the DMAEMA monomer to form the PDMAEMA gel or the alkyl radical copolymerizes the proton-depleted PEI with the DMAEMA monomer.

In order to explore more favourable preparation conditions for the PEI/PDMAEMA gel on the basis of the above synthetic method, the effects of PEI concentration (0-8\%), reaction time (1-6 h), and temperature $\left(30-90{ }^{\circ} \mathrm{C}\right)$ on the adsorption capacity $\left(\mathrm{mg} \mathrm{g}^{-1}\right)$ were investigated successively. It was found that as the concentration of PEI in the reaction solution increased, the adsorption amount of the anions became higher, which indicated that the introduction of PEI increased the number of functional amine groups in the gel, significantly improving the adsorption performance of the gel for the anions. However, when the PEI concentration in the solution was further increased from $5 \%$ to a higher level, some liquid would remain after the reaction was completed, making the gel sticky and therefore, its morphology was not ideal. On the whole, 5\% PEI was very suitable. As for the reaction temperature, it is another crucial condition for the gel and the related polymerization only occurred above $65{ }^{\circ} \mathrm{C}$. Moreover, the reaction was an endothermic process, so as the reaction temperature became higher, the reaction rate together with the crosslinking density would increase.$^{20}$ When the temperature was $85{ }^{\circ} \mathrm{C}$, the adsorption amount reached the highest level with satisfactory gel polymerization degree. If the temperature continued to increase, the polymer would form too fast, resulting in shorter cross-linking points and a denser structure, which is not conducive to obtain ideal adsorption performance. Finally, the results showed that when the reaction time was $3 \mathrm{~h}$, the adsorption amount of the gel was the highest; it would decrease as the reaction time became longer. The reason was that the amine groups on the polyethyleneimine in the gel inevitably underwent deactivation at a higher temperature for a long time,,$^{\mathbf{2 1 , 2 2}}$ thus resulting in a decrease in the adsorption capacity.

\section{Effect of adsorption time on the adsorption capacity for the anions on the PEI/PDMAEMA gel}

Under the conditions of $\mathrm{pH} 2.0$ and $40{ }^{\circ} \mathrm{C}$, the effect of adsorption time on the adsorption performance for amaranth and sunset yellow with an initial concentration of $1000 \mathrm{mg} \mathrm{g}^{-1}$ on 0.05 g PDMAEMA gel adsorbent (ED 0, which means PEI concentration $=0 \%$ ) or PEI/PDMAEMA gel (ED 5, which means PEI concentration $=5 \%$ ) were investigated. Fig. 1 (a) shows the effect of adsorption time on the adsorption capacity. In general, a high adsorption rate can effectively shorten the interaction time, which is a guarantee for efficient work of adsorbent materials in practical applications. For these two kinds of anionic dyes, it was found that the adsorption process of amaranth and sunset yellow on different gels is very similar, which includes surface diffusion adsorption (the first stage, fast) and pore diffusion adsorption (the second stage, slow). However, ED 5 shows higher adsorption rate than ED 0; the time to reach full adsorption equilibrium is reduced from 360 minutes to 120 minutes and the speed is increased by nearly 3 times. Moreover, the adsorption for amaranth, which has more anionic sites, increased faster than that for sunset yellow and 


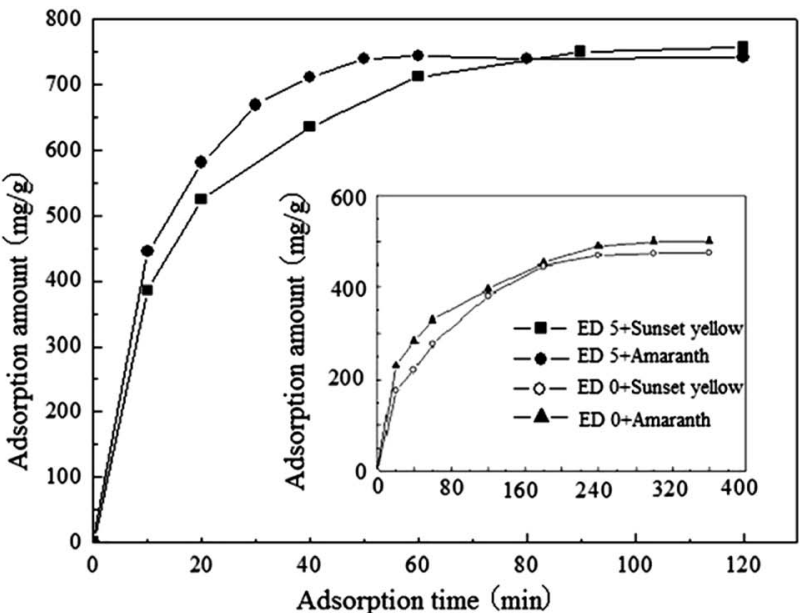

(a)

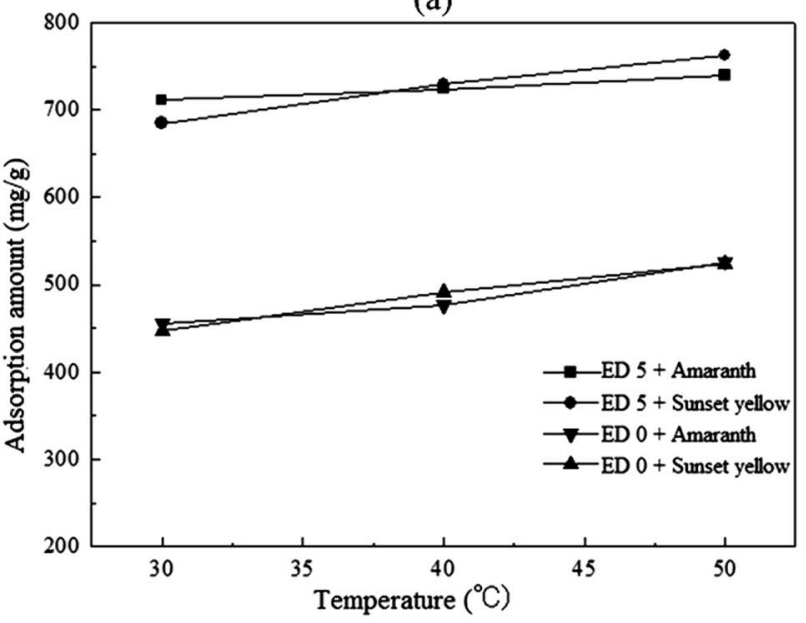

(c)

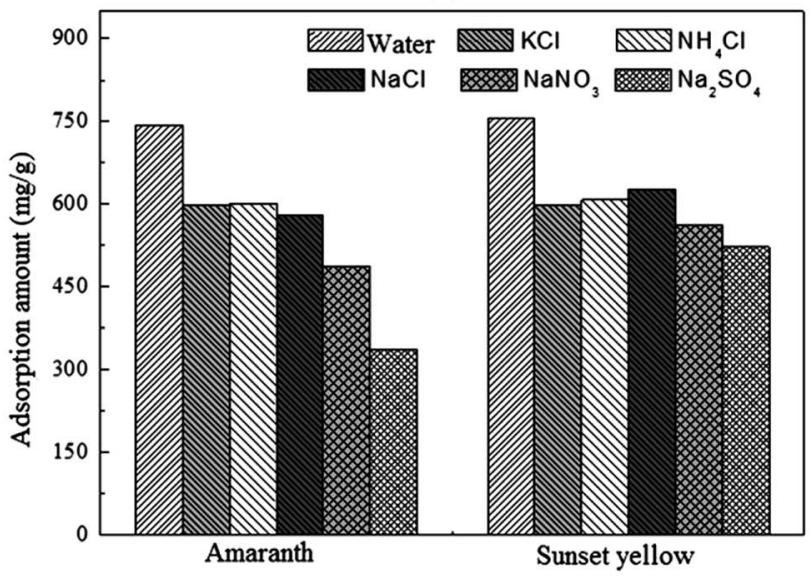

(e)

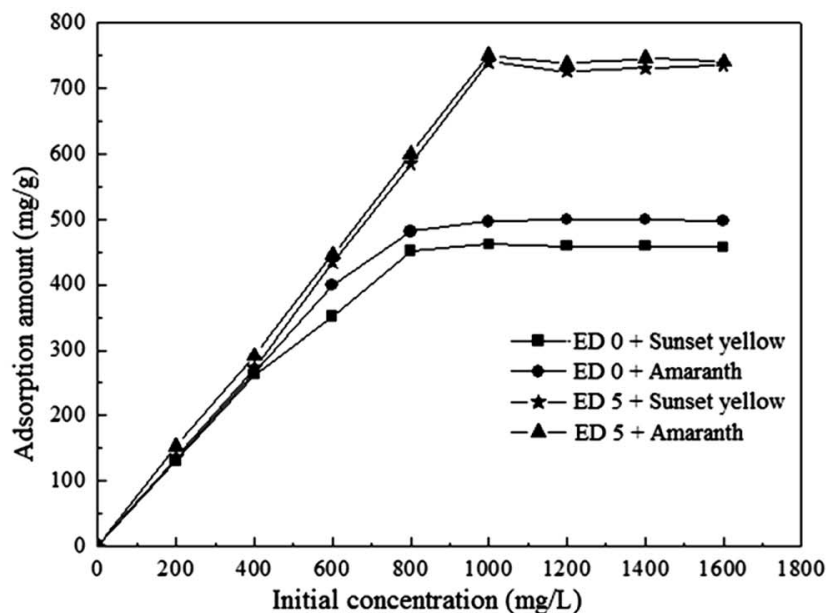

(b)

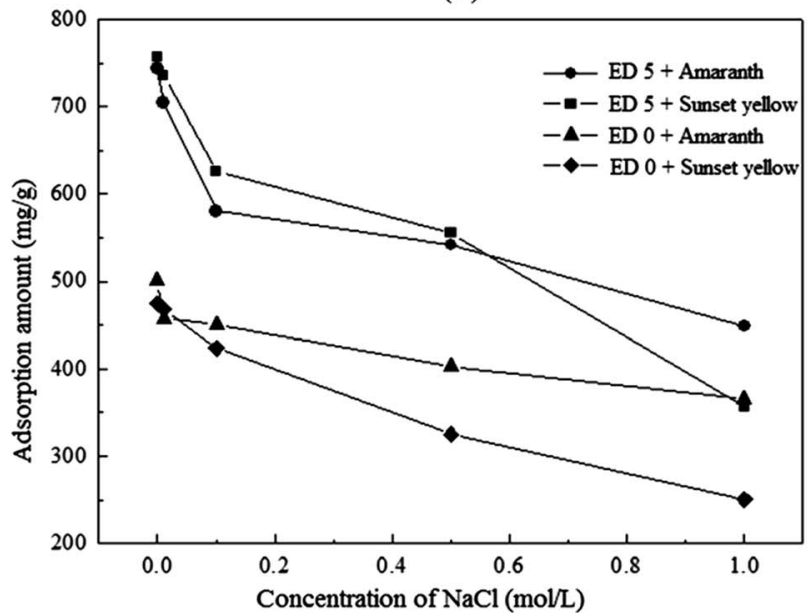

(d)

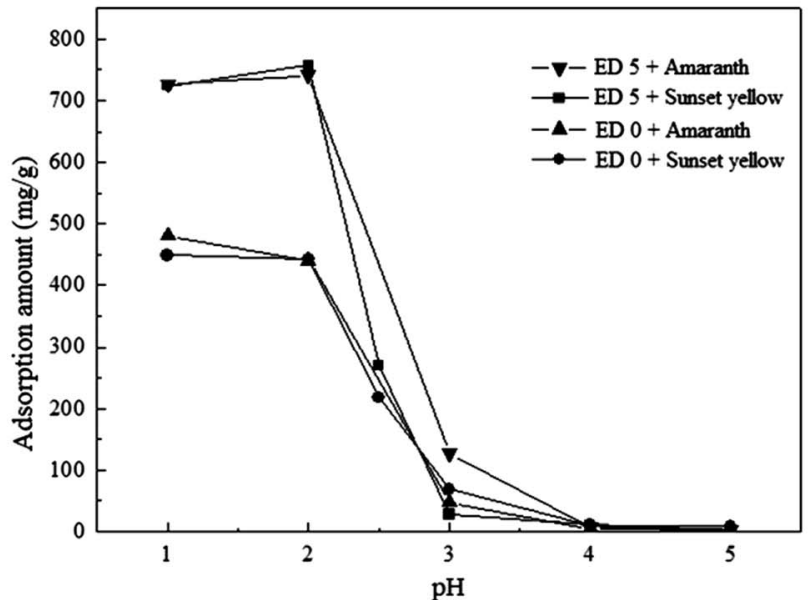

(f)

Fig. 1 Effects of the separation conditions on the adsorption amount of the dyes: (a) adsorption time ( $\mathrm{pH}=2, T=40^{\circ} \mathrm{C}$ ), (b) initial concentration $\left(\mathrm{pH}=2, T=40^{\circ} \mathrm{C}, 5 \mathrm{~h}\right),(\mathrm{c})$ temperature $(\mathrm{pH}=2,5 \mathrm{~h})$, (d) ionic strength $\left(\mathrm{pH}=2, T=40^{\circ} \mathrm{C}, 5 \mathrm{~h}\right)$, (e) ionic species $\left(\mathrm{pH}=2, T=40^{\circ} \mathrm{C}, 5 \mathrm{~h}\right),(\mathrm{f}) \mathrm{pH}(\mathrm{T}=$ $\left.40{ }^{\circ} \mathrm{C}, 5 \mathrm{~h}\right)$.

the two curves approached each other after attaining full equilibrium.

In further analysis, it was found that ED 0 had an equilibrium adsorption time of $5 \mathrm{~h}$ for amaranth and sunset yellow, and the maximum adsorption amounts are $501.43 \mathrm{mg} \mathrm{g}^{-1}$ and $475.23 \mathrm{mg}$ $\mathrm{g}^{-1}$, respectively. The equilibrium adsorption time of ED 5 for the two anionic dyes was $1 \mathrm{~h}$, and the maximum adsorption capacities were $744.14 \mathrm{mg} \mathrm{g}^{-1}$ and $757.10 \mathrm{mg} \mathrm{g}^{-1}$, respectively. This may be because the introduction of polar polyethyleneimine (PEI) increases the hydrophilicity of the gel and the number of amine 
functional groups, which facilitates the contact of the gel with the anions. At the same time, it also provides more adsorption sites for anions under acidic conditions.

The adsorption properties of various adsorbent materials for amaranth and sunset yellow in recent years are summarized in Table $1 .^{23-41}$ Through comparison, it can be found that the adsorption capacity for sunset yellow on PEI/PDMAEMA gel exceeds that of most other adsorbents, while the adsorption capacity for amaranth is significantly higher than that for other adsorbents. Moreover, the contact time of the adsorbents in this table ranges from 5 minutes to 30 hours; among these, the adsorption time on the PEI/PDMAEMA gel is one hour, which demonstrates that this kind of adsorption method can combine high adsorption efficiency and satisfactory separation speed.

\section{Effect of initial concentration on the adsorption capacity for the anions on the PEI/PDMAEMA gel}

In order to investigate the effect of the initial concentration of the anion solution on the adsorption amount, the initial concentration of amaranth and sunset yellow varied from $200 \mathrm{mg} \mathrm{L}^{-1}$ to $1600 \mathrm{mg} \mathrm{L}^{-1}$ when the other conditions remained unchanged (adsorption temperature: $40{ }^{\circ} \mathrm{C}$, the amount of adsorbent: $0.05 \mathrm{~g}, \mathrm{pH}$ : 2.0, adsorption time: $5 \mathrm{~h}$ ).
According to the results shown in Fig. 1(b), it can be found that as the initial sample concentration increases, the amount of anion adsorbed by the PEI/PDMAEMA composite increases. At low levels of initial concentration ( $400 \mathrm{mg} \mathrm{L}^{-1}$ or less), ED 5 and ED 0 have similar adsorption performance for the two anionic dyes. When the initial concentration is between $400 \mathrm{mg} \mathrm{L}^{-1}$ and $800 \mathrm{mg} \mathrm{L}^{-1}$, the adsorption capacity of ED 5 for the two anionic dyes is slightly greater than that of ED 0 . In the whole investigated concentration range, both the anionic dyes reached saturated adsorption at an initial concentration of $1000 \mathrm{mg} \mathrm{L}^{-1}$. The adsorption amount of ED 5 is significantly larger than ED 0, which indicates that the introduction of hydrophilic polyethyleneimine (PEI) facilitates the binding of the gel to the anion. However, it is not obvious at lower concentrations of the dyes.

\section{Effect of temperature on the adsorption capacity for the anions on the PEI/PDMAEMA gel}

In order to investigate the effect of temperature on the adsorption performance, the adsorption temperature was set in the range of $25-60{ }^{\circ} \mathrm{C}$, the $\mathrm{pH}$ value of the solution was 2.0 , the adsorbent dosage was $0.05 \mathrm{~g}$, the adsorption time was $5 \mathrm{~h}$, and the initial concentration of amaranth or sunset yellow was $1.0 \mathrm{~g}$

Table 1 Adsorption capacity for AM and SY FCF among different adsorbents ${ }^{23-41}$

\begin{tabular}{|c|c|c|c|}
\hline Anionic dyes & Adsorbents & Adsorption capacity $\left(\mathrm{mg} \mathrm{g}^{-1}\right)$ & Adsorption time \\
\hline \multirow[t]{19}{*}{ Sunset yellow FCF } & Mangrove barks & 12.72 & $5 \mathrm{~h}$ \\
\hline & Powdered peanut hull & 13.99 & $36 \mathrm{~h}$ \\
\hline & Ag-NP-AC & 37.03 & $30 \mathrm{~min}$ \\
\hline & Amberlite FPA51 & 48.7 & $20 \mathrm{~min}$ \\
\hline & CdTN-AC & 61.31 & $28 \mathrm{~min}$ \\
\hline & $\mathrm{Cd}(\mathrm{OH})_{2}-\mathrm{NW}-\mathrm{AC}$ & 76.9 & $25 \min$ \\
\hline & MPMWCNT nanocomposite & 85.47 & $6 \mathrm{~h}$ \\
\hline & $\begin{array}{l}\text { Molecularly imprinted polymer } \\
\text { nanoparticles }\end{array}$ & 144.6 & $5 \mathrm{~min}$ \\
\hline & ePTFE- $g$-PDMAEMA & 170.61 & - \\
\hline & $\mathrm{CaAl}-\mathrm{LDH}-\mathrm{NO}_{3}$ & 398.41 & $50 \mathrm{~min}$ \\
\hline & Multiwalled carbon nanotubes (MWCNTs) & 59.17 & $5 \mathrm{~min}$ \\
\hline & PDVB-IL & 734.62 & $5 \mathrm{~h}$ \\
\hline & Conventional poly(DMAEMA) (PD) & 501.43 & $5 \mathrm{~h}$ \\
\hline & Macroporous poly(DMAEMA) (MD) & 525.03 & $2 \mathrm{~h}$ \\
\hline & PEI- $g$-PDMAEMA (ED) in this study & 744.14 & $1 \mathrm{~h}$ \\
\hline & Iron oxide nanoparticles & 1.05 & $5 \mathrm{~min}$ \\
\hline & Mesoporous carbon modified with cerium & 323.91 & $70 \mathrm{~min}$ \\
\hline & Alumina reinforced polystyrene & 8.281 & $2 \mathrm{~h}$ \\
\hline & Powdered peanut hull & 14.9 & $36 \mathrm{~h}$ \\
\hline \multirow[t]{14}{*}{ Amaranth } & MPMWCNT nanocomposite & 47.39 & $6 \mathrm{~h}$ \\
\hline & $\mathrm{Fe}_{3} \mathrm{O}_{4} / \mathrm{ZrO}_{2} /$ chitosan & 99.6 & $8 \mathrm{~h}$ \\
\hline & ePTFE- $g$-PDMAEMA & 173.29 & - \\
\hline & Chitosan films & 278.3 & $2 \mathrm{~h}$ \\
\hline & Cellulose carbon-encapsulated $\mathrm{ZnO}$ & 396 & $3 \mathrm{~h}$ \\
\hline & (PES/PEI) nanofibrous membrane & 454.44 & $14 \mathrm{~h}$ \\
\hline & PDVB-IL & 547.17 & $5 \mathrm{~h}$ \\
\hline & CSU-1(150) & 650 & $24 \mathrm{~h}$ \\
\hline & PE- $g$-PDMAEMA & 737.21 & $30 \mathrm{~h}$ \\
\hline & Conventional poly(DMAEMA) (PD) & 475.23 & $5 \mathrm{~h}$ \\
\hline & Macroporous poly(DMAEMA) (MD) & 510.57 & $2 \mathrm{~h}$ \\
\hline & PEI- $g$-PDMAEMA (ED) in this study & 757.10 & $1 \mathrm{~h}$ \\
\hline & $\mathrm{MgAlCO}_{3}$ & 120.90 & $3 \mathrm{~h}$ \\
\hline & Magnetic $\mathrm{Fe}_{3} \mathrm{O}_{4} / \mathrm{MgO}$ nanoparticles & 37.98 & - \\
\hline
\end{tabular}


$\mathrm{L}^{-1}$. The effect of adsorption temperature on the adsorption performance of the gel is shown in Fig. 1(c).

In depth, the adsorption involves two processes: one is the protonation process of the amine groups on the PEI/PDMAEMA gel, which is an exothermic process, where high temperatures are harmful to the protonation of the amine groups. The other is the adsorption process between the positively charged amine groups and the anions, which is an endothermic process. ${ }^{24}$ Therefore, in the adsorption process of the anionic dyes, as the adsorption temperature increases, the adsorption amount of PEI/PDMAEMA for amaranth or sunset yellow can also increase. It indicates that the adsorption process for the anionic dyes amaranth and sunset yellow is an endothermic process. This result is consistent with the adsorption behaviour of anionic dyes on most of the adsorbents listed in Table 1 or some other magnetic polymers. ${ }^{42}$ The net effect of exothermic and endothermic stages leads to the conclusion that a higher temperature is more favourable for adsorption.

\section{Effect of ionic strength on the adsorption capacity for the anions on the PEI/PDMAEMA gel}

In order to study the effect of ionic strength on the adsorption performance of the PEI/PDMAEMA gel, both the initial concentrations of amaranth and sunset yellow were $1.0 \mathrm{~g} \mathrm{~L}^{-1}$ in their solutions with $\mathrm{pH}$ 2.0. The experiments were performed using $0.05 \mathrm{~g}$ adsorbent at $40{ }^{\circ} \mathrm{C}$ for $5 \mathrm{~h}$ adsorption and the concentration of the $\mathrm{NaCl}$ solution was investigated at the of 0 , $0.01,0.1,0.5$, and $1.0 \mathrm{~mol} \mathrm{~L}^{-1}$ concentration levels. The effect of ionic strength on the adsorption performance for amaranth and sunset yellow is shown in Fig. 1(d).

It can be seen that the adsorption amount of the PEI/ PDMAEMA gel for amaranth and sunset yellow decreases rapidly with the increase in the $\mathrm{NaCl}$ concentration in the solution. The possible reason is ascribed to the fact that the anion $\mathrm{Cl}^{-}$in the solution can compete with the anionic sulfonic acid group in the dyes, which is not conducive to the electrostatic interactions between the anionic adsorbate and the amine active sites $\left(-\mathrm{NH}_{3}{ }^{+},-\mathrm{NH}_{2}{ }^{+}\right.$, and $\left.-\mathrm{N}^{+} \mathrm{HMe}_{2}\right)$. Moreover, high concentrations of $\mathrm{Na}^{+}$and $\mathrm{Cl}^{-}$ions can destroy the electrical double layer around the gel surface. Therefore, the adsorption capacity of PEI/PDMAEMA gel for amaranth and sunset yellow decreases rapidly with the increase in the ionic strength.

\section{Effect of ionic species on the adsorption capacity for the anions on the PEI/PDMAEMA gel}

In order to further study the potential effects of ionic species on the adsorption properties of the gels, the tested inorganic salts were divided into two groups: cationic group $\left(\mathrm{KCl}, \mathrm{NH}_{4} \mathrm{Cl}\right.$, and $\mathrm{NaCl})$ and anionic group $\left(\mathrm{NaCl}, \mathrm{NaNO}_{3}\right.$, and $\left.\mathrm{Na}_{2} \mathrm{SO}_{4}\right)$. Both the initial concentrations of amaranth and sunset yellow solutions were $1.0 \mathrm{~g} \mathrm{~L}^{-1}$, the temperature was set at $40{ }^{\circ} \mathrm{C}$, the adsorbent dosage was $0.05 \mathrm{~g}$, the adsorption time was $5 \mathrm{~h}$, and the solution $\mathrm{pH}$ was 2.0. The concentration of $\mathrm{KCl}, \mathrm{NH}_{4} \mathrm{Cl}, \mathrm{NaCl}, \mathrm{NaNO}_{3}$, and $\mathrm{Na}_{2} \mathrm{SO}_{4}$ solutions was $0.1 \mathrm{~mol} \mathrm{~L}^{-1}$. The effect of ionic species on the adsorption performance for amaranth and sunset yellow is shown and compared in Fig. 1(e).

Obviously, the addition of coexisting ions reduced the adsorption amount of anions on the PEI/PDMAEMA gel. This is because the anions $\mathrm{SO}_{4}{ }^{2-}, \mathrm{Cl}^{-}$, and $\mathrm{NO}_{3}{ }^{-}$in the solution can compete with the target anions $\mathrm{AM}^{-}, \mathrm{SY} \mathrm{FCF}^{-}$, and $\mathrm{SY} \mathrm{FCF}^{2-}$, thereby reducing their adsorption capacity. In addition, it can be seen from this figure that $\mathrm{SO}_{4}{ }^{2-}$ ion has a significant negative effect on the adsorption by the PEI/PDMAEMA gel. Particularly, when the same concentration of $\mathrm{Na}_{2} \mathrm{SO}_{4}$ was added in the process of amaranth adsorption, the adsorption amount obviously reduced. The influence of $\mathrm{K}^{+}, \mathrm{Na}^{+}, \mathrm{NH}_{4}{ }^{+}, \mathrm{Cl}^{-}$, and $\mathrm{NO}_{3}{ }^{-}$ ions on the adsorption performance of the gel is relatively smaller. This is consistent with the findings of a previous study. $^{43}$

\section{Effect of solution $\mathrm{pH}$ on the adsorption capacity for the anions on the PEI/PDMAEMA gel}

$\mathrm{pH}$ is an important factor that affects the existing status of the ionic species together with the adsorption performance of the PEI/PDMAEMA gel. In this experiment, both the initial concentrations of amaranth and sunset yellow solutions were $1.0 \mathrm{~g} \mathrm{~L}^{-1}$, the temperature was set to $40{ }^{\circ} \mathrm{C}$, the adsorbent dosage was $0.05 \mathrm{~g}$, and the adsorption time was $5 \mathrm{~h}$. The $\mathrm{pH}$ values of the amaranth and sunset yellow solutions are adjusted to $1,2,2.5,3,4$, and 5 . The amine nitrogen atom on PEI and DMAEMA, which has a pair of electrons, is regarded as the active site of the reaction between the gel and the anions. As seen in Fig. 1(f), the adsorption amount of amaranth and sunset yellow on the PEI/PDMAEMA gel decreases with increase in the $\mathrm{pH}$ of the solution. When the $\mathrm{pH}$ value is in the range of 1-2, the adsorption capacity of ED 5 and ED 0 for the two anionic dyes is larger. Moreover, the adsorption amount decreases rapidly between $\mathrm{pH}$ 2-3 and when the $\mathrm{pH}$ dropped to 5, the adsorption amount was close to zero. The functional groups on PEI/ PDMAEMA, such as amine, imine, and dimethylamine $\left(-\mathrm{NH}_{2}\right.$, $-\mathrm{NH}-$, and $-\mathrm{NMe}_{2}$ ), bind to $\mathrm{H}^{+}$at low $\mathrm{pH}$ to form active sites $\left(-\mathrm{NH}_{3}{ }^{+},-\mathrm{NH}_{2}{ }^{+}-\right.$, and $\left.-\mathrm{N}^{+} \mathrm{HMe}_{2}\right)$, which can interact with the anions more strongly.

Particularly, after the adsorption was performed under acidic conditions, its volume significantly shrunk and a large amount of bubbles were generated during the adsorption process. Scanning electron microscopy was used to observe the morphology of PEI/PDMAEMA before and after the adsorption of amaranth and sunset yellow dyes (see Fig. 2). The results show that before the anion adsorption, the surface of PEI/ PDMAEMA is dense and smooth, and after the adsorption of a large amount of anionic dyes, a large number of encapsulated particles appear on the surface of the gel, with large accumulation of pores also visible on its surface. This should be related to the ability to generate bubbles during the PEI/PDMAEMA adsorption process.

\section{Adsorption isotherms}

In order to further investigate the adsorption behaviour and adsorption mechanism of the PEI/PDMAEMA gel for amaranth 

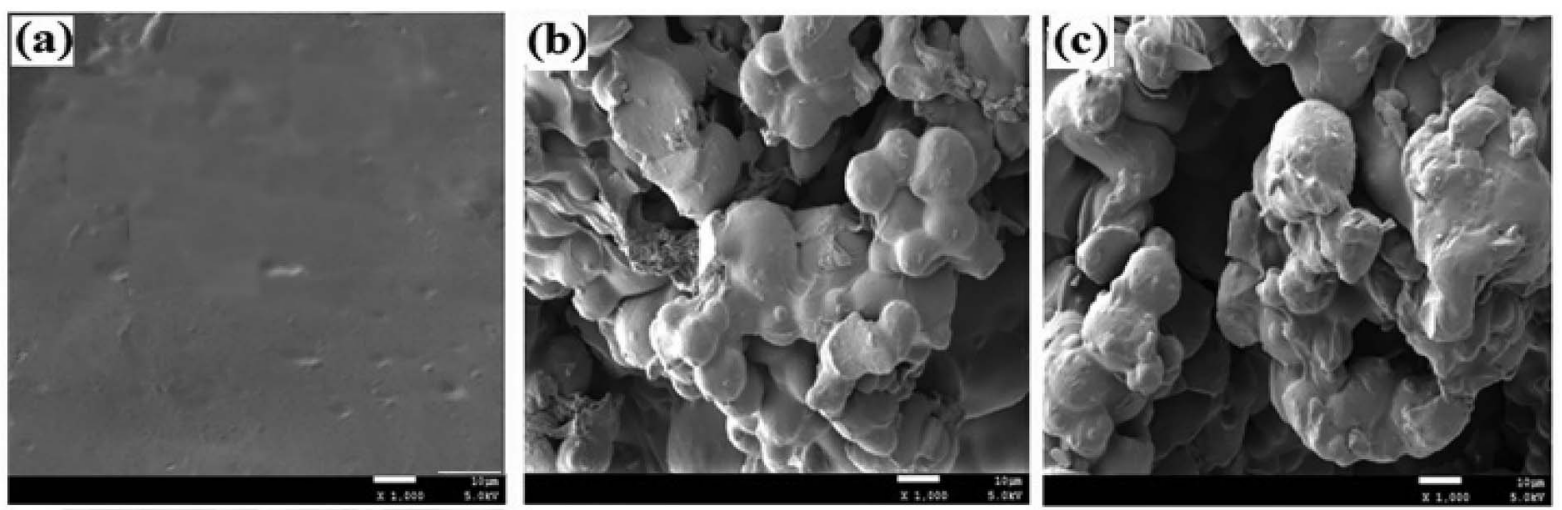

Fig. 2 SEM images of the PEI/PDMAEMA hydrogels ((a) PEI/PDMAEMA, (b) after adsorbing amaranth, and (c) after adsorbing sunset yellow).

and sunset yellow, the Langmuir and Freundlich adsorption isotherms were used to fit the experimental data after adsorption equilibrium, as shown in Fig. 3(a and b). Moreover, Table 2 shows the fitting constants for the Langmuir and Freundlich models. It can be seen from the table that the experimental data conform to the Langmuir isotherm adsorption model. In other words, the anion undergoes single-layer adsorption on the surface of the PEI/PDMAEMA composite and there is no mutual interference between the adsorbates. Also, the results are consistent with a previous study, where the PEI/DMAEMA gel was used to adsorb $\mathrm{Cr}(\mathrm{vI}) ;{ }^{16}$ the results indicated that the sitespecific interactions between the PEI binding sites and $\mathrm{CrO}_{4}{ }^{2-}$ also led to the Langmuir type isotherm, and the adsorbent surface was homogeneous. In addition, under different adsorption conditions, the values of RL for the target dyes adsorbed by the PEI/PDMAEMA composites are between 0 and 1 , indicating that the adsorption process of the two anions on the gel is occurs easily.

\section{Adsorption kinetics}

In order to further investigate the adsorption process of the PEI/ PDMAEMA gel for amaranth and sunset yellow, pseudo firstorder kinetics, pseudo second-order kinetics, and intraparticle diffusion model were used to fit the experimental data after adsorption equilibrium was attained. The linear relationship and correlation coefficients after fitting are shown in Fig. 3(c and d) and Table 3.

It can be found that the maximum theoretical adsorption amount $\left(Q_{e, \text { cal }}\right)$ for the pseudo second-order kinetic model is closer to the experimental maximum adsorption amount. The maximum theoretical adsorption capacity $\left(Q_{e, \text { cal }}\right)$ of the pseudo first-order kinetic model is significantly different from the experimental value. Moreover, the linear correlation coefficient $\left(R^{2}\right)$ of all the pseudo second-order kinetic models is above 0.99, indicating that the adsorption behaviour of the PEI/PDMAEMA gel are in accordance with the pseudo second-order kinetic model. When the gel was used to adsorb $\mathrm{CrO}_{4}{ }^{2-}$, the pseudo second-order equation also fitted well with the experimental data and could describe the adsorbent behaviour well. ${ }^{40}$ Moreover, this kind of model was feasible for describing the adsorption process involved in the removal of amaranth by nanoparticle-composed $\mathrm{Cu}_{2} \mathrm{O}$ microspheres. ${ }^{44}$ The intraparticle diffusion model shows that the linear fitting correlation under several adsorption conditions is low and neither of them passes through the origin after linear fitting. Therefore, it can be concluded that the surface active sites of the adsorbent have significant influence on the adsorption behaviour for amaranth and sunset yellow.

\section{Adsorption thermodynamics}

The equilibrium constant of $K_{\mathrm{d}}$ was calculated by measuring the adsorption amount of the PEI/PDMAEMA gel on amaranth and sunset yellow at different temperatures, and the related thermodynamic plots are shown in Fig. 3(e). Furthermore, the relevant thermodynamic data are summarized in Table 4.

It can be seen that the PEI/PDMAEMA gel has a negative Gibbs free energy $(\Delta G)$ for amaranth and sunset yellow at different adsorption temperatures and for different anionic dyes. This indicates that the adsorption process for amaranth and sunset yellow by PEI/PDMAEMA is spontaneous. The positive value of entropy change $(\Delta S)$ indicates that the entropy increases during the adsorption process, indicating that the movement of the adsorbate molecules is freer in the solution than those on the surface of the gel and the reaction system is in a disordered state, which can be explained by the displacement adsorption theory. In other words, in the adsorption process, $\mathrm{Cl}^{-}$is replaced by the anionic adsorbates and enters the solution, resulting in an increase in the degree of disorder of the adsorption system.

The enthalpy change $(\Delta H)$ in the gel during the adsorption of amaranth and sunset yellow was positive in the range from $2 \mathrm{~kJ} \mathrm{~mol}^{-1}$ to $10 \mathrm{~kJ} \mathrm{~mol}^{-1}$, indicating that the adsorption of amaranth and sunset yellow by the PEI/PDMAEMA gel is an endothermic process, which is in agreement with the conclusion of the effect of temperature on adsorption and the nature of adsorption is more physical than chemical. In the study of selective adsorption of amaranth dye on $\mathrm{Fe}_{3} \mathrm{O}_{4} / \mathrm{MgO}$ nanoparticles performed by Salem et al. ${ }^{38}$ the values of $\Delta H$ and $\Delta S$ are positive, which indicates that the adsorption process is endothermic with the increase in the randomness of the 


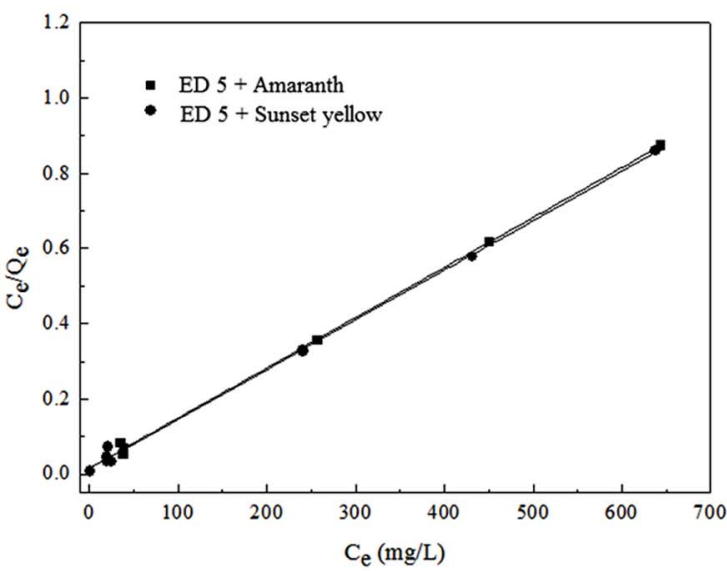

(a)

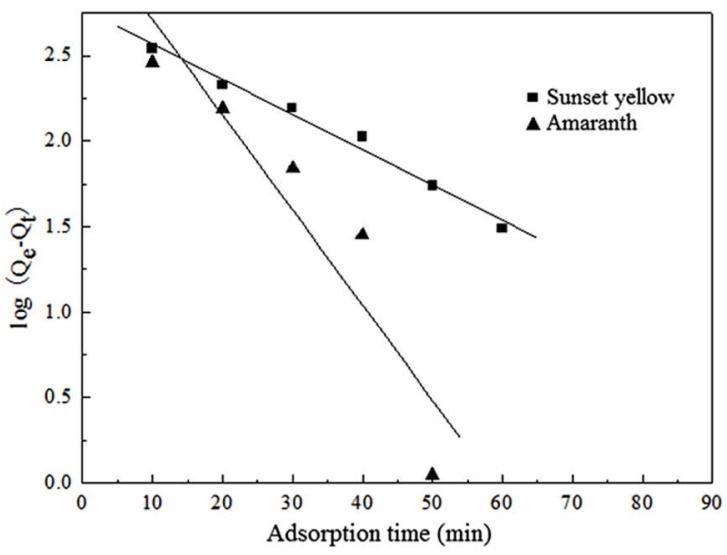

(c)

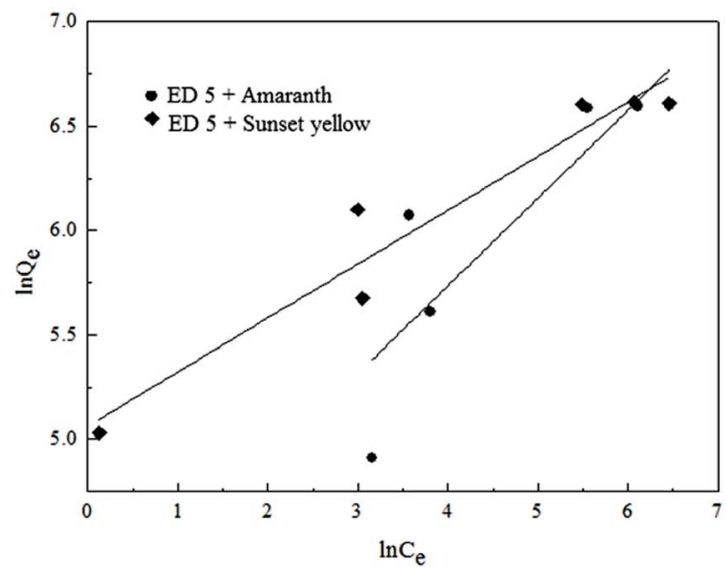

(b)

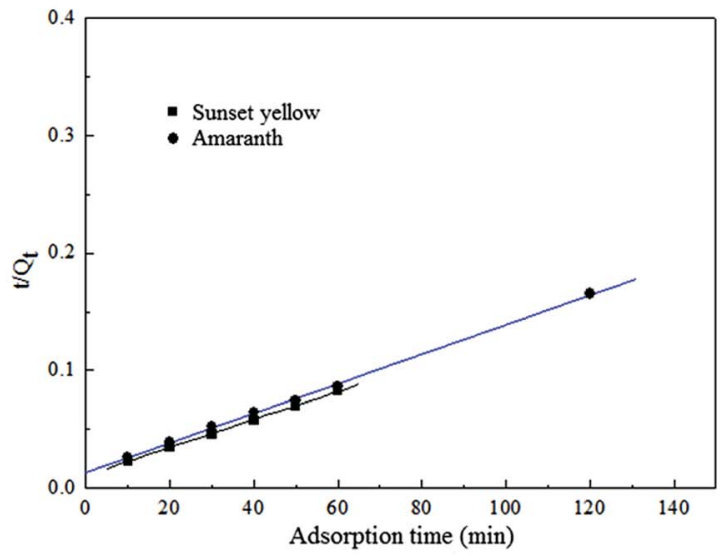

(d)

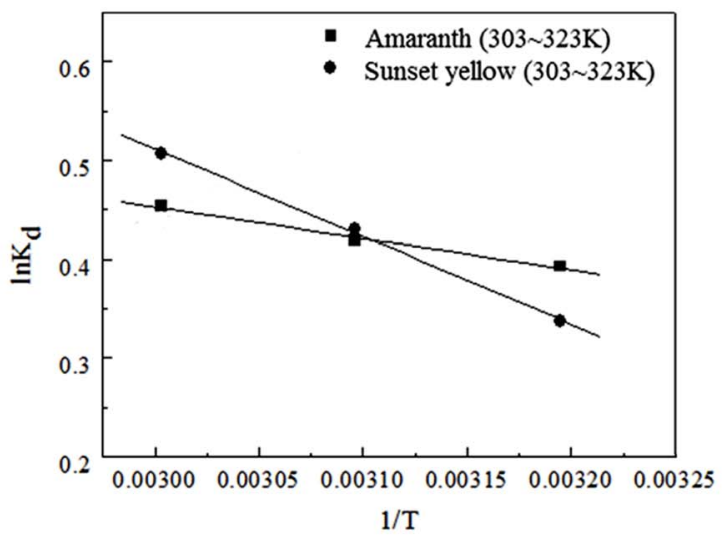

(e)

Fig. 3 Adsorption behaviours of AM and SY FCF on the PEI/PDMAEMA gels ((a) Langmuir isotherm model, (b) Freundlich isotherm model, (c) pseudo first-order kinetic model, (d) pseudo second-order kinetic model, (e) thermodynamic plots).

Table 2 Langmuir and Freundlich constants for adsorption of the anions on the PEI/PDMAEMA hydrogels

\begin{tabular}{|c|c|c|c|c|c|c|c|}
\hline Adsorption behavior & \multicolumn{4}{|c|}{ Langmuir constants } & \multicolumn{3}{|c|}{ Freundlich constants } \\
\hline ED 5 (SY FCF) & 757.58 & 0.094 & 0.998 & $0.051-0.001$ & 158.31 & 3.872 & 0.919 \\
\hline
\end{tabular}


Table 3 The comparison of pseudo first-order, pseudo second-order, and intraparticle diffusion kinetic models' rate constants calculated from the experimental data

\begin{tabular}{|c|c|c|c|c|c|c|c|c|}
\hline SY FCF & 715.2 & 0.049 & 0.9851 & 840.3 & 0.0001 & 0.9993 & 66.278 & 0.7691 \\
\hline
\end{tabular}

Table 4 Values of the thermodynamic parameters for the adsorption of AM and SY FCF on the PEI/PDMAEMA gel

\begin{tabular}{lllll}
\hline Adsorbate & $T(\mathrm{~K})$ & $\begin{array}{l}\Delta G \\
\left(\mathrm{~kJ} \mathrm{~mol}^{-1}\right)\end{array}$ & $\begin{array}{l}\Delta S \\
\left(\mathrm{~J}\left(\mathrm{~mol}^{-1} \mathrm{~K}^{-1}\right)\right)\end{array}$ & $\begin{array}{l}\Delta H \\
\left(\mathrm{~kJ} \mathrm{~mol}^{-1}\right)\end{array}$ \\
\hline \multirow{2}{*}{ AM } & 303 & -0.989 & 11.69 & 2.643 \\
& 313 & -1.09 & & \\
& 323 & -1.212 & & \\
SY SCF & 303 & -0.849 & & 7.366 \\
& 313 & -1.12 & 26.35 &
\end{tabular}

system. Based on the results, the adsorption process of amaranth and sunset yellow by the PEI/PDMAEMA gel is spontaneous and the adsorption mechanism includes two kinds of possible ways: ion exchange between $\mathrm{Cl}^{-}$and anion adsorbate together with electrostatic interaction between the amine-based positive charge and anions on the gel. Among them, the electrostatic effect plays a dominant role in the adsorption mechanism.

\section{Adsorption mechanism for the anion on the PEI/PDMAEMA gel}

Besides the former isotherm, kinetic, and thermodynamic studies, the IR and zeta potential measurements were also used to investigate the adsorption mechanism. First, the FT-IR spectra (PerkinElmer, USA) obtained in $\mathrm{KBr}$ discs for the PEI/ PDMAEMA gel before and after the adsorption of amaranth and sunset yellow are shown in Fig. 4(a-c). Similar to previous results, the IR spectrum of the PEI/PDMAEMA composite showed the characteristic absorption peaks of the PDMAEMA gel. ${ }^{45}$ As shown in Fig. 4(a), the absorption peak at $1727 \mathrm{~cm}^{-1}$ is ascribed to the stretching vibration of the - $\mathrm{COO}-$ group; the peak in the range of $3000-2280 \mathrm{~cm}^{-1}$ belonged to the $\mathrm{C}-\mathrm{H}$ symmetric/asymmetric stretching vibration of the dimethylamino group; the absorption signal at $1177 \mathrm{~cm}^{-1}$ corresponded to the stretching vibration of the alkyl chain $\mathrm{C}-\mathrm{N}$. Moreover, the ED gel has a strong broad peak at $3437 \mathrm{~cm}^{-1}$, which is the characteristic absorption peak of $\mathrm{O}-\mathrm{H}$ and $\mathrm{N}-\mathrm{H}$ stretching vibrations; the adsorption peak between 3000 and $2800 \mathrm{~cm}^{-1}$ belongs to the $\mathrm{C}-\mathrm{H}$ symmetry/asymmetry stretching vibrations of the dimethylamino group; the peak at $1650 \mathrm{~cm}^{-1}$ is ascribed to the $\mathrm{N}-\mathrm{H}$ bending vibration. These peaks indicated that PEI had been successfully introduced into the PEI/PDMAEMA composites. Moreover, the zeta potential analysis indicated that the PEI/PDMAEMA gel was positively charged under acidic conditions, which was closely related to the amino groups $\left(-\mathrm{NH}_{2},-\mathrm{NH}-\right.$, and $\left.-\mathrm{NMe}_{2}\right)$ that combined with a large amount of protons.

Second, as can be seen from Fig. 4(b and c), compared with the IR spectrum before adsorption, an aromatic characteristic peak at $900-600 \mathrm{~cm}^{-1}$ and a $-\mathrm{SO}_{3}{ }^{-}$absorption peak at $1035 \mathrm{~cm}^{-1}$ appeared in the IR spectrum of (b) and (c), which indicates that amaranth and sunset yellow are adsorbed on the gel material. In the IR spectra of (b) and (c) after the adsorption of anions, the intensity of the $\mathrm{N}-\mathrm{H}$ bending vibrational peak at $1650 \mathrm{~cm}^{-1}$ becomes significantly weakened. On the curves of amaranth (b) and sunset yellow (c), the dimethylamino group peak between 3000 and $2900 \mathrm{~cm}^{-1}$ disappeared. This indicates that the amino environment on the PEI/PDMAEMA gel changed after the adsorption. Therefore, it can be inferred that the

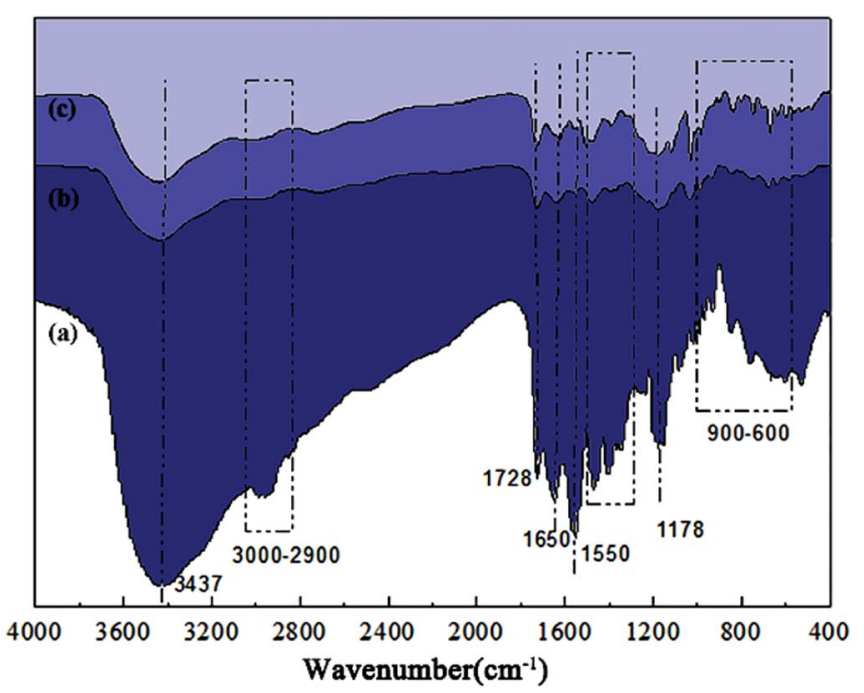

(d) before adsorption (e)after adsorption

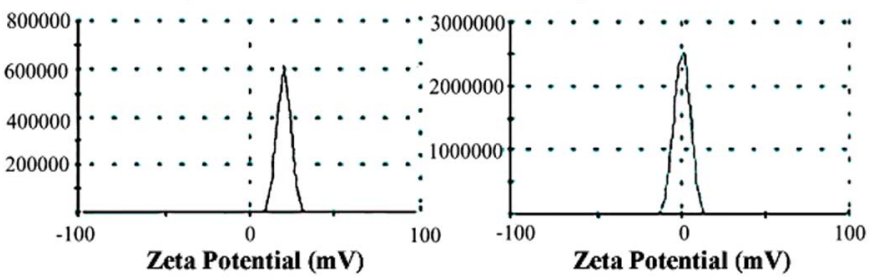

Fig. 4 FT-IR spectra before and after the adsorption of anions on the PEI/PDMAEMA hydrogel ((a) ED; (b) ED + AM; (c) ED + SY FCF) and the zeta potential distribution of ED before (d) and after (e) the adsorption of SY FCF. 
amino groups play a major role in the adsorption of amaranth and sunset yellow on this composite gel.

In general, the solid-liquid adsorption process is very complicated due to various solute-interface interactions. ${ }^{46} \mathrm{~A}$ variety of adsorption theories (electrical double layer theory, membrane theory, lattice theory etc.) have been proposed. Among them, the electrical double layer theory has been continuously developed and used by researchers to discover the adsorption mechanism of cations and anions. ${ }^{47}$ According to the Stern electric double layer theory, when the solid and liquid phase contact each other, the solid surface tends to have a charging phenomenon, which causes the liquid side of the solid-liquid interface to carry an opposite charge. This interfacial charge affects the distribution of ions in the medium surrounding the biphasic interface, thus forming a compact layer (Stern layer) and an external dispersion layer (Gou layer) around the interface. ${ }^{48}$

The mechanism was also discovered using a PALS Zeta Potential Analyzer (Version 3.43, Brookhaven Instruments, USA). For the PEI/PDMAEM gels, the amino, imino, and dimethylamino functional groups $\left(-\mathrm{NH}_{2},-\mathrm{NH}-\right.$, and $\left.-\mathrm{NMe}_{2}\right)$ are capable of binding to $\mathrm{H}^{+}$ions in solution as a positively charged interface. Amaranth and sunset yellow can dissociate into anionic groups in solution. When the gel is dispersed in such an anionic dye, it interacts with the anion on the cationic gel, which forms the electrical double layer to reduce the potential on the surface of the gel (see Fig. $4\left(\mathrm{~d}\right.$ and e)). ${ }^{49}$ This can also provide an explanation for the aforementioned phenomenon that after anion adsorption, the density of the same charge ion decreases and the repulsive force is weakened, which causes the gel to shrink.

In addition, according to Stern's study, the adsorption in the Stern layer satisfies the Langmuir monolayer adsorption model, which is consistent with our previous isothermal adsorption fitting results. Based on the above analysis, the main adsorption process of anionic dyes on the PEI/PDMAEMA gel is depicted in Fig. 5.

\section{Breakthrough curves for dynamic adsorption}

According to the former sections for the static experiments, the PEI/PDMAEMA gel shows both high adsorption capacity and

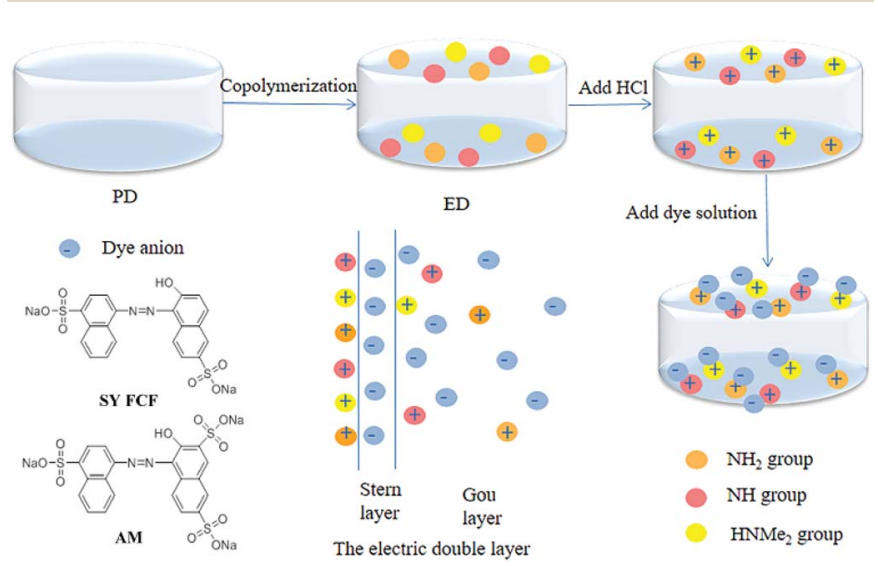

Fig. 5 The adsorption mechanism of dye anions onto the polymers. short adsorption time, and these advantages also exist when it is applied in the form of a fixed bed adsorbent. In order to further investigate the potential for practical applications of the PEI/PDMAEMA gel, the ability of the PEI/PDMAEMA gel to remove sunset yellow in aqueous solution by means of a fixed bed/continuous flow column and the effect of different sunset yellow concentrations on the breakthrough curve were studied. The flow rate was maintained at $0.2 \mathrm{~mL} \mathrm{~min}^{-1}$. The penetration curve of the PEI/PDMAEMA gel against sunset yellow at different injection concentrations is shown in Fig. 6(a).

Obviously, higher the concentration of sunset yellow, steeper is the penetrating curve, and thus, earlier is the appearance of the saturation point of adsorption for sunset yellow on the PEI/ PDMAEMA gel. Before the breakthrough curve reaches the saturation point, $204 \mathrm{~mL}$ and $280 \mathrm{~mL}$ of sunset yellow solution with a loading concentration of $200 \mathrm{mg} \mathrm{L}^{-1}$ and $400 \mathrm{mg} \mathrm{L}^{-1}$, respectively, can be processed. The dynamic adsorption capacities were $332.3 \mathrm{mg} \mathrm{g}^{-1}$ and $487.3 \mathrm{mg} \mathrm{g}^{-1}$, respectively, which were $55.3 \%$ and $34.5 \%$ lower than the static saturated adsorption capacity, respectively. It could be found that as the concentration of the sample solution increases, the adsorption amount of sunset yellow on the PEI/PDMAEMA gel also increases but the time to reach the saturation point is shortened. The results show that a low concentration of the sample solution can handle a larger sample volume and extend the operation life of the gel column, which make it better for practical application.

\section{Penetration curve model for dynamic adsorption}

To better describe the PEI/PDMAEMA gel dynamic column adsorption behaviour, both Thomas and Adams-Bohart models were used to correlate the dynamic adsorption data as shown in Fig. 6(b and c) and the fitting parameters are included in Table 5.

It can be seen from Table 5 that the Thomas model $\left(R^{2}\right.$ values of 0.911 and 0.934 for the two dyes) is more suitable than the Adams-Bohart model ( $R^{2}$ values of 0.725 and 0.774$)$ to describe the fixed bed dynamic adsorption experimental data of the PEI/ PDMAEMA gel for sunset yellow. As the concentration increases, the $K_{\mathrm{T}}$ value decreases. In the fixed-bed adsorption column, the sunset yellow anions in the solution only contact the adsorption column at a limited layer thickness and the number of adsorption sites is also limited. At a certain flow rate, only part of the sunset yellow anions will be bound onto the adsorption sites. Most of the anions flow out of the adsorption column with continuous sample loading, resulting in a very low mass transfer of the sunset yellow anions from the liquid phase to the solid phase; it further leads to a lower removal efficiency at higher initial concentrations.

\section{Static desorption study for gel regeneration}

The desorption operation can obtain a concentrated solution of amaranth and sunset yellow, which is beneficial for recovering the anions and regenerating the adsorbent for repeated use, thus making the adsorption process more economical and feasible. Herein, $\mathrm{NaOH}$ solution was used as the eluent under 


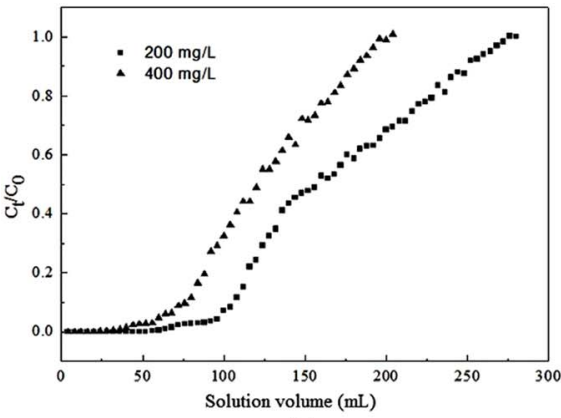

(a)

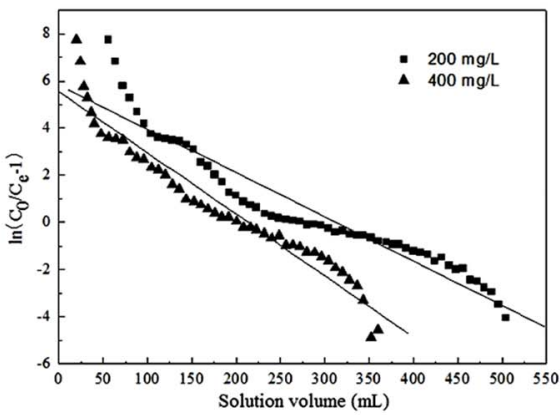

(b)

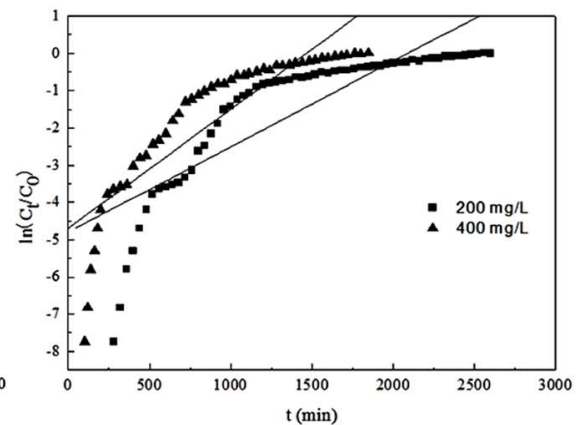

(c)

Fig. 6 Curves for the adsorption of SY FCF on the PEI/PDMAEMA gels ((a) breakthrough curves, (b) Thomas fitting curves, (c) Adams-Bohart curves).

Table 5 Parameters of the Thomas and Adams-Bohart models under different conditions using linear regression analysis

\begin{tabular}{llll}
\hline \multirow{2}{*}{$\begin{array}{l}\text { Concentration } \\
\left(\mathrm{mg} \mathrm{L}^{-1}\right)\end{array}$} & \multicolumn{2}{l}{ Thomas } & \multicolumn{2}{l}{\begin{tabular}{l} 
Adams-Bohart \\
\cline { 2 - 3 }
\end{tabular}} & $K_{\mathrm{T}}\left(\mathrm{mL} \mathrm{min}^{-1} \mathrm{mg}^{-1}\right)$ & $R^{2}$ & $K_{\mathrm{AB}} \times 10^{4}\left(\mathrm{~L} \mathrm{mg}^{-1} \mathrm{~min}^{-1}\right)$ \\
\hline 200 & 0.0187 & 0.911 & 0.115 \\
400 & 0.0130 & 0.934 & 0.08
\end{tabular}

Table 6 Ratio of desorption of AM and SY FCF from the PDMAEMA gels by $\mathrm{NaOH}$ solution

\begin{tabular}{lllll}
\hline Adsorbate & Eluent & $\begin{array}{l}\text { First desorption } \\
\text { rate }\end{array}$ & \multicolumn{2}{l}{$\begin{array}{l}\text { Second desorption } \\
\text { rate }\end{array}$} \\
\hline AM & $\mathrm{NaOH}\left(0.1 \mathrm{~mol} \mathrm{~L}^{-1}\right)$ & $82.42 \%$ & $10.28 \%$ & $92.7 \%$ \\
SY FCF & $\mathrm{NaOH}\left(0.1 \mathrm{~mol} \mathrm{~L}^{-1}\right)$ & $89.09 \%$ & $9.09 \%$ & $98.18 \%$
\end{tabular}

the investigated conditions. It was found in the static adsorption experiments that the $\mathrm{pH}$ of the solution can significantly affect the action of the amine group on the anion and the composite. Under alkaline conditions, it is not suitable for the removal of the anionic adsorbate. Therefore, in the static desorption experiment, $\mathrm{NaOH}$ solution with the $\mathrm{pH}$ value of 10 and concentration of $0.1 \mathrm{~mol} \mathrm{~L}^{-1}$ was proved to be the ideal eluent. In order to increase the desorption efficiency of the anionic dye, the tested desorption liquid was divided into two parts to carry out the elution. As a result, the desorption effect from the PEI/PDMAEMA gel on amaranth and sunset yellow is shown in Table 6.

It could be found that the total desorption rates of amaranth and sunset yellow reached $92.7 \%$ and $98.18 \%$, respectively. The results showed that in order to obtain a satisfactory desorption effect, the dye concentration in the desorption solution should be less than $2 \mathrm{mg} \mathrm{mL}^{-1}$. In order to further observe the gel reusability, the gel obtained after desorbing the two dyes was washed with redistilled water until neutral and was then repeatedly used five times. The results indicated that the adsorption amount only dropped by $5.8 \%$ and $6.7 \%$. As intuitive evidence, Fig. 7 shows the static adsorption-desorption process for the two anionic dyes on the conventional PDMAEMA gel
(PD), the macroporous PDMAEMA gel (MD), and the PEI/ PDMAEMA (ED) gels.

\section{Dynamic desorption study}

The dynamically adsorbed gel short column was eluted with $0.1 \mathrm{~mol} \mathrm{~L}^{-1} \mathrm{NaOH}$ solution at a flow rate of $0.5 \mathrm{~mL} \mathrm{~min}^{-1}$. The elution curve is shown in Fig. 8. The results prove that the concentration of sunset yellow in the eluent is large at the initial

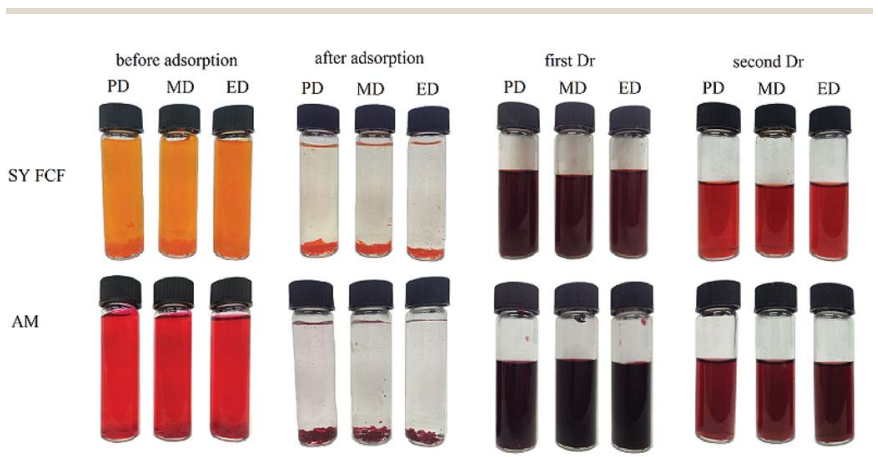

Fig. 7 The process of adsorption and desorption of anionic dyes on ED, MD and PD hydrogels. 


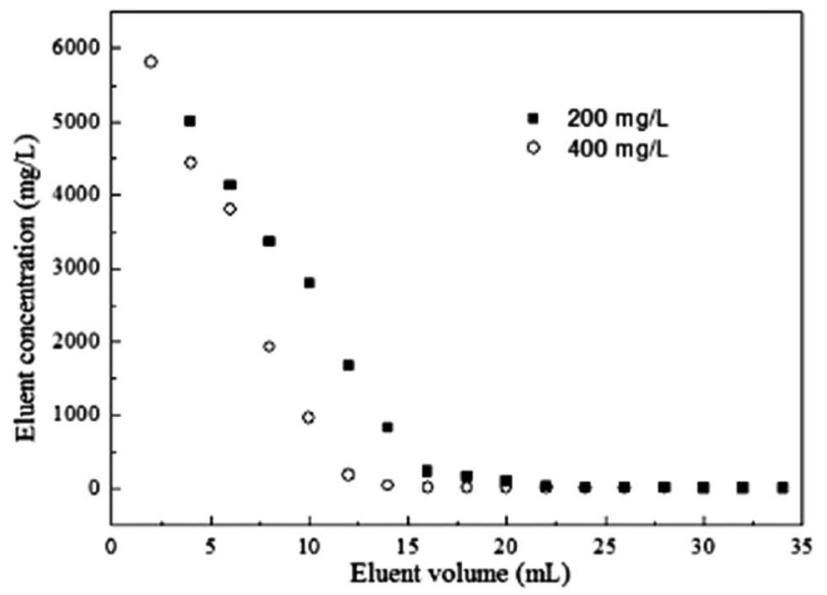

Fig. 8 Elution curves for desorption of SY FCF.

stage of dynamic desorption. The eluent volume required for a low initial concentration to achieve complete desorption is also smaller. For example, when the concentration in the solution approaches zero, a $200 \mathrm{mg} \mathrm{L}^{-1}$ adsorption column requires $28 \mathrm{~mL}$ of eluent and a $400 \mathrm{mg} \mathrm{L}^{-1}$ adsorption column requires $34 \mathrm{~mL}$ of $\mathrm{NaOH}$ as the eluent. The data show that the gel has a high desorption efficiency and concentration ability during the regeneration process, which is beneficial for the reuse of the gel and the recovery of the adsorbents after their enrichment. Through the above regeneration ways, the PEI/ PDMAEMA gel could be reused at least five times.

\section{Conclusions}

In this study, the composite adsorbent PEI/PDMAEMA was first synthesized by radical polymerization, which avoids the traditional complex grafting process. According to the results, the introduction of PEI significantly increased the adsorption speed and adsorption capacity of the PDMAEMA gel for amaranth and sunset yellow. Both the adsorption equilibrium of the PEI/ PDMAEMA composite gel (ED 5) for amaranth and sunset yellow could be reached within $1 \mathrm{~h}$ and the maximum adsorption amount was $757 \mathrm{mg} \mathrm{g}^{-1}$ and $744 \mathrm{mg} \mathrm{g}^{-1}$, respectively. In addition, the PEI/PDMAEMA composite gel is sensitive to $\mathrm{pH}$ and lower ionic strength is more conducive for the adsorption of anions by the PEI/PDMAEMA gel. Moreover, the $\mathrm{SO}_{4}{ }^{2-}$ ion has a more significant effect on the adsorption amount than other inorganic anions and cations, which is consistent with the reported properties of the PDMAEMA gel. The separation mechanism of the above dyes on the PEI/PDMAEMA gel was mainly via electrostatic adsorption, which was consistent with the double layer adsorption process.

On the other hand, when the PEI/PDMAEMA gel was used in the fixed bed (continuous flow column), it could handle large volumes of the sunset yellow solution with very low concentrations, which indicated its strong enrichment capacity. The adsorption of the anions by the PEI/PDMAEMA gel conformed to the Langmuir adsorption isotherm model and the pseudo second-order kinetic model, which was a spontaneous endothermic process. At last, the desorption experiments show that the PEI/PDMAEMA gel is easier to regenerate and has a longer operation life. Although the research for this kind of new adsorption materials is just at the beginning stage, the good properties and ease of operation indicate the possibility of wide applications of this useful gel for the removal of more pollutants.

\section{Conflicts of interest}

There are no conflicts to declare.

\section{Acknowledgements}

Preparation of this paper was supported by the National Natural Science Foundation of China (No. 21706240, 81673316) and 2017 "Stars of Chemical Engineering" outstanding young talent training program of Sichuan University.

\section{Notes and references}

1 A. Ahmad, S. H. Mohd-Setapar, C. S. Chuong, A. Khatoon, W. A. Wani, R. Kumar and M. Rafatullah, Recent advances in new generation dye removal technologies: novel search for approaches to reprocess wastewater, $R S C A d v$., 2015, 5, 30801-30818.

2 M. Oplatowska-Stachowiak and C. T. Elliott, Food colours: existing and emerging food safety concerns, Crit. Rev. Food Sci. Nutr., 2017, 57, 524-548.

$3 \mathrm{H}$. Zeng and R. C. Tang, Adsorption properties of direct dyes on viscose/chitin bicomponent fiber: evaluation and comparison with viscose fiber, $R S C$ Adv., 2014, 4, 3806438072.

4 C. Gao, J. Chen, C. Chen and M. Liu, Physicochemical characterization and drug release properties of PDMAEMA/ OSA Semi-IPN hydrogels with microporous structure, Polym. Adv. Technol., 2012, 23, 389-397.

5 E. S. Dragan, M. Bercea and L. Sacarascu, Tuning the associative properties and micelles geometry by stepwise quaternization of PDMAEMA, React. Funct. Polym., 2018, 124, 171-180.

6 Y. Berbar, M. Amara and H. Kerdjoudj, Effect of Adsorption of polyethyleneimine on the behaviour of anion exchange resin, Procedia Eng., 2012, 33, 126-133.

7 B. Gao, Y. Li and F. An, Preparation of iminoacetic acid-type composite chelating material IAA-PEI/SiO ${ }_{2}$ and preliminary studies on chelating adsorption property towards heavy metal ions, J. Macromol. Sci., Part A: Pure Appl.Chem., 2011, 48, 823-831.

8 Y. Li, B. Gao and R. Du, Studies on Preparation and recognition characteristic of surface-ion imprinting material IIP-PEI/SiO $\mathrm{Si}_{2}$ of chromate anion, Sep. Sci. Technol., 2011, 46, 1472-1481.

$9 \mathrm{~N}$. Ishihara and $\mathrm{H}$. Tokuyama, Temperature-swing adsorption of precious metal ions onto poly(2(dimethylamino)ethyl methacrylate) gel, React. Funct. Polym., 2010, 70, 610-615. 
10 Y. Zhou, Y. Hu, W. Huang, G. Cheng, C. Cui and J. Lu, Adsorption of $\mathrm{Cr}$ (VI) ions using the amphiphilic gels based on 2-(dimethylamino) ethyl methacrylate modified with 1-bromoalkanes, Chem. Eng. J., 2018, 341, 47-57.

11 L. Xu, Q. Cheng and C. Li, Adsorption of Cr (VI) ions using the amphiphilic gels based on 2-(dimethylamino) ethyl methacrylate modified with 1-bromoalkanes, Chem. Eng. J., 2011, 173, 42-48.

12 L. Shen, M. Min and G. Hong, Micro-nano structure poly (ether sulfones)/poly (ethyleneimine) nanofibrous affinity membranes for adsorption of anionic dyes and heavy metal ions in aqueous solution, Chem. Eng. J., 2012, 197, 88-100.

13 Y. Zhang, J. Li, J. Zhao, Y. Zhang and J. Fan, Utilization of modified Dioscorea opposita Thunb. as a novel biosorbent for the adsorption of indigo carmine in aqueous solutions, RSC Adv., 2018, 8, 30040-30048.

14 H. Gao, T. Kan, S. Zhao, Y. Qian, X. Cheng, W. Wu, X. Wang and L. Zheng, Removal of anionic azo dyes from aqueous solution by functional ionic liquid cross-linked polymer, $J$. Hazard. Mater., 2013, 261, 83-90.

15 A. T. Bisgin, Simultaneous preconcentration and determination of brilliant blue and sunset yellow in foodstuffs by solid-phase extraction combined UV-vis spectrophotometry, J. AOAC Int., 2018, 101, 1850-1856.

16 Z. Hou, W. Zhu, H. Song, P. Chen and S. Yao, The adsorption behavior and mechanistic investigation of $\mathrm{Cr}(\mathrm{VI})$ ions removal by poly(2-(dimethylamino)ethyl methacrylate)/ poly(ethyleneimine) gels, J. Serb. Chem. Soc., 2015, 80, 889902.

17 X. L. Du, Q. P. Yuan, Y. Li and H. H. Zhou, Preparative purification of solanesol from tobacco leaf extracts by macroporous resins, Chem. Eng. Technol., 2008, 31, 87-94.

$18 \mathrm{~K}$. Zhang and H. J. Choi, Fabrication and viscoelastic characteristics of amino-functionalized multi-walled carbon nanotube/poly(methyl methacrylate) nanocomposites, Compos. Struct., 2015, 125, 170-175.

19 X. Liu, M. Sun, Z. Wu, L. Ding and G. Zhai, $\mathrm{Cu}^{\mathrm{I}}$-catalyzed aerobic oxidation of tertiary amines as chain initiation for radical polymerization of methyl methacrylate. Syndiotactic-rich alpha-amino PMMA via mono-centered initiation, Appl. Catal., A, 2016, 522, 1-12.

20 S. H. Kang, S. G. Kim and H. S. Lee, Synthesis of poly(nisopropylacrylamide) micro-hydrogel using a microfluidic channel and study on concentration sensor, Polymer, 2018, 42, 1052-1058.

21 W. Choi, K. Min, C. Kim, Y. S. Ko, J. W. Jeon, H. Seo, Y. K. Park and M. Choi, Epoxide-functionalization of polyethyleneimine for synthesis of stable carbon dioxide adsorbent in temperature swing adsorption, Nat. Commun., 2016, 7, 12640.

22 D. V. Quang, A. V. Rabindran, N. E. Hadri and M. R. M. AbuZahra, Reduction in the regeneration energy of $\mathrm{CO}_{2}$ capture process by impregnating amine solvent onto precipitated silica, Eur. Sci. J., 2013, 9, 82-102.

23 K. Yamada, M. Shibuya, C. Takagi and M. Hirata, Adsorption and desorption properties of cationic polyethylene film gels to organic anions and their regeneration, J. Appl. Polym. Sci., 2006, 99, 381-391.

24 R. Kumar and R. Ahmad, Adsorption of amaranth dye onto alumina reinforced polystyrene, Clean: Soil, Air, Water, 2011, 39, 74-82.

25 B. K. Suyamboo and R. S. Perumal, Equilibrium, thermodynamic and kinetic studies on adsorption of a basic dye by Citrullus lanatus rind, Iran. J. Energy Environ., 2012, 3, 23-34.

26 H. Jiang, P. Chen, S. Luo, X. Tu, Q. Cao, Y. Zhou and W. Zhang, Synthesis of novel biocompatible composite $\mathrm{Fe}_{3} \mathrm{O}_{4} / \mathrm{ZrO}_{2} /$ chitosan and its application for dye removal, $J$. Inorg. Organomet. Polym. Mater., 2013, 23, 393-400.

27 Y. Ding, Y. Sun, M. li, R. Gong, H. Liu and C. Yang, Utilization of powdered peanut hull as biosorbent for removal of anionic dyes from aqueous solution, Dyes Pigm., 2005, 64, 187-192.

28 M. Ghaedi, Comparison of cadmium hydroxide nanowires and silver nanoparticles loaded on activated carbon as new adsorbents for efficient removal of Sunset yellow: kinetics and equilibrium study, Spectrochim. Acta, Part A, 2012, 94, 346-351.

29 M. Wawrzkiewicz, Sorption of Sunset Yellow dye by weak base anion exchanger-kinetic and equilibrium studies, Environ. Technol., 2011, 32, 455-465.

30 M. K. Purkait, S. Khodadoust, A. Mihandoost, R. Sahraei, M. Ghaedi, A. Daneshfar and A. Hekmati Jah, Cadmium telluride nanoparticles loaded on activated carbon as adsorbent for removal of sunset yellow, Spectrochim. Acta, Part A, 2012, 90, 22-27.

$31 \mathrm{H}$. Gao, S. Zhao and X. Cheng, Removal of anionic azo dyes from aqueous solution using magnetic polymer multi-wall carbon nanotube nanocomposite as adsorbent, Chem. Eng. J., 2013, 223, 84-90.

32 K. Yamada, C. Takagi and M. Hirata, Adsorption and desorption properties of expanded poly (tetrafluoroethylene) films grafted with DMAEMA and their regeneration, J. Appl. Polym. Sci., 2007, 104, 3301-3308.

33 F. Pereira de Sá, B. N. Cunha and L. M. Nunes, Effect of pH on the adsorption of Sunset Yellow FCF food dye into a layered double hydroxide (CaAl-LDH-NO $\mathrm{N}_{3}$ ), Chem. Eng. J., 2013, 215/216, 122-127.

34 G. L. Dotto and L. A. A. Pinto, Adsorption of food dyes onto chitosan: optimization process and kinetic, Carbohydr. Polym., 2011, 84, 231-238.

35 R. Ahmad and R. Kumar, Synthesis and properties of cellulose carbon encapsulated $\mathrm{ZnO}$ for dye removal, $J$. Dispersion Sci. Technol., 2011, 32, 737-740.

36 J. T. Li, B. L. Li and H. C. Wang, A wormhole-structured mesoporous carbon with superior adsorption for dyes, Carbon, 2011, 49, 1912-1918.

37 K. Abdellaoui, I. Pavlovic, M. Bouhent, A. Benhamou and C. Barriga, A comparative study of the amaranth azo dye adsorption/desorption from aqueous solutions by layered double hydroxides, Appl. Clay Sci., 2017, 143, 142-150. 
38 A. N. M. Salem, M. A. Ahmed and M. F. El-Shahat, Selective adsorption of amaranth dye on $\mathrm{Fe}_{3} \mathrm{O}_{4} / \mathrm{MgO}$ nanoparticles, $J$. Mol. Liq., 2016, 219, 780-788.

39 R. Karimi, F. Yousefi, M. Ghaedi, K. Dashtian and M. Montazerozohori, Efficient adsorption of erythrosine and sunset yellow onto modified palladium nanoparticles with a 2-diamine compound: application of multivariate technique, J. Ind. Eng. Chem., 2017, 48, 43-55.

40 Y. Zhang, Z. Xie, X. Teng and J. Fan, Synthesis of molecularly imprinted polymer nanoparticles for the fast and highly selective adsorption of sunset yellow, J. Sep. Sci., 2016, 39, 1559-1566.

41 J. Goscianska, M. Marciniak and R. Pietrzak, Ordered mesoporous carbons modified with cerium as effective adsorbents for azo dyes removal, Sep. Purif. Technol., 2015, 154, 236-245.

42 M. Y. Arica, G. Bayramoglu and B. Altintas, Synthesis and characterization of magnetic beads containing aminated fibrous surfaces for removal of Reactive Green 19 dye: kinetics and thermodynamic parameters, J. Chem. Technol. Biotechnol., 2012, 87, 705-713.

43 Y. Wen, Z. Tang and Y. Chen, Adsorption of Cr (VI) from aqueous solutions using chitosan-coated fly ash composite as biosorbent, Chem. Eng. J., 2011, 175, 110-116.
$44 \mathrm{H}$. Liao and Z. Wang, Adsorption removal of amaranth by nanoparticles-composed $\mathrm{Cu}_{2} \mathrm{O}$ microspheres, J. Alloys Compd., 2018, 769, 1088-1095.

45 Y. Chen, Synthesis and characterization of $\mathrm{pH}$ and temperature double-sensitive nanocomposite hydrogels consisting of poly (dimethylaminoethyl methacrylate) and clay, J. Mater. Res., 2013, 28, 1394-1404.

46 F. V. Pereira, L. V. A. Gurgel and L. F. Gil, Removal of $\mathrm{Zn}^{2+}$ from aqueous single metal solutions and electroplating wastewater with wood sawdust and sugarcane bagasse modified with EDTA dianhydride (EDTAD), J. Hazard. Mater., 2010, 176, 856-863.

47 N. P. Qafoku, E. V. Ranst, A. Noble and G. Baert, Variable charge soils: their mineralogy, chemistry and management, Adv. Agron., 2004, 84, 159-215.

48 M. A. Brown, B. Guilherme Volpe and M. Sylvio, Emergence of a stern layer from the incorporation of hydration interactions into the Gouy-Chapman model of the electrical double layer, Langmuir, 2015, 31, 11477-11483.

49 T. Hou, R. Xu, D. Tiwari and A. Zhao, Interaction between electrical double layers of soil colloids and $\mathrm{Fe} / \mathrm{Al}$ oxides in suspensions, J. Colloid Interface Sci., 2007, 310, 670-674. 